\title{
Complementary and alternative medicine (CAM): a comparative study between nursing and medical students
}

\section{Intan Idiana Hassan, Nurul Husna Abd Hadi, Soon Lean Keng}

Nursing School of Health Sciences, Health Campus, Universiti Sains Malaysia, Kota Bharu, Kelantan, Malaysia

\section{ARTICLE INFO}

Received : :28/02/2012

Accepted : : 17/05/2012

Published : :01/12/2012

\section{KEYWORD}

Knowledge

Attitude

Practice

Complementary medicine

Alternative medicine

Nursing student

Medical student

\section{ABSTRACT}

In recent years, the popularity of using complementary and alternative medicine (CAM) as a health care option has increased dramatically all over the world especially in developing countries. As Malaysian statistics showed an increased in chronic diseases among our population, the demand to consume CAM for healing process as well as in pursuit of health and well-being also has increased. Thus it increased patient's interest to request more information from medical practitioners and nurses who are front health care providers. The objective of this study is to compare the knowledge, attitudes, and practice (KAP) of CAM among final year nursing and medical students in Universiti Sains Malaysia (USM). A crosssectional comparative study was conducted among final year medical and nursing students using self administered questionnaire. This study utilized the Knowledge-Attitude-Practice (KAP) model to explain how level of knowledge may reflect nursing and medical students' attitudes and practice of CAMs. There were 74 students participated where 33 of them were nursing students, and 41 were medical students. Independent t-test was used to compare the KAP of CAM between both groups of students and there was a significant different. As a conclusion, this study revealed that nursing students were more knowledgeable about CAM, possessed positive attitudes, and more willing to practice CAM compared to medical students.

(C) Medical Education Department, School of Medical Sciences, Universiti Sains Malaysia. All rights reserved.

CORRESPONDING AUTHOR: Intan Idiana Hassan, School of Health Sciences, Health Campus, Universiti Sains Malaysia, Kota Bharu, Kelantan, Malaysia,

Email: idiana@kk.usm.my, intanidiana@yahoo.com 


\section{Introduction}

Complementary and alternative medicine (CAM) has been defined as a group of diverse medical and health care systems, practices and products that are not generally considered part of conventional medicine. In recent years, the popularity of using CAM as a health care option has increased dramatically all over the world especially in developing countries [1]. The World Health Organization (WHO) estimated that in many countries, $80 \%$ or more of the population living in the rural area are cared for by traditional practitioners [2]. The tendency toward incorporating CAM as an integrative model of care is most evident in areas in which comfort care becomes a priority such as oncology and palliative care [3]. As a result of increasing chronic diseases according to Malaysian Department of Statistics 2007, the demand of practicing CAMs among patients also increased [4]. Thus it increased patient's interest to request more information from medical practitioners and nurses who are front health care providers [1].

A study by Nabilla et al. on CAM utilization among Malaysian health care professionals revealed that $14.9 \%$ of medical practitioners were exposed to CAM during their undergraduate days, while $27.1 \%$ used CAMs on themselves or their own families, and $22.2 \%$ have referred their patients to CAM practitioners [3].CAM therapies involved phytopharmacological actions and interactions with other medication [5]. It is therefore crucial for nurses, physicians, as well as nursing and medical students to have basic knowledge on the indications and contraindications of CAMs use.

Thus the objective of this study was to compare the knowledge, attitudes, and practice (KAP) of CAM among final year nursing and medical students in Universiti Sains Malaysia (USM).

\section{Method}

A cross-sectional comparative study was conducted among final year medical and nursing students in 2011. All students involved with clinical session were included. Self-administered questionnaire was adapted and modified from several questionnaires [6-10]. This study utilized the Knowledge-Attitude-Practice (KAP) model to explain how level of knowledge may reflect nursing and medical students' attitudes and practice of CAMs [11]. A pilot study was conducted and Cronbach's alpha obtained was 0.878. The questionnaire was distributed and collected at the same time. The questionnaire consists of knowledge about CAM, general attitudes towards CAM and CAM approaches in clinical practice.

This questionnaire focuses on 16 CAM modalities; acupuncture, aromatherapy, chiropractic, creative therapies, diet/nutritional therapies, herbal therapies, homeopathy, magnetic healing, massage therapy, meditation, prayer, qi gong, reflexology, relaxation techniques, therapeutic touch, and tonic products. The items were rated using Likertscale. All data were analyzed using Statistical Package for Social Sciences (SPSS) version 18. Independent t-test was used to compare the KAP of CAM between nursing and medical students.

\section{Result}

\section{Differences of CAM knowledge among nursing and medical students}

Nursing and medical students showed that they were well known about prayer (table 1) because the mean scored was highest compared to other modalities. 9 items among

16 modalities in knowledge measurement; aromatherapy, creative therapies, diet therapies, magnetic healing, massage therapy, meditation, prayer, qi gong and therapeutic touch, showed a significantly different where nursing students scored each of these items higher than medical students.

\section{Differences of Attitude towards CAMs among Nursing and Medical Student}

Table 2 represents that both groups scored the lowest mean when they were asked whether 
'CAM therapies should be offered to patients only when no real cause or cure can be found,' and was assumed to reflect that they possessed negative attitude towards it. Nursing students showed the highest mean score which meant possessed positive attitude towards item 'all health care professionals should have some knowledge about the most common CAM therapies' compared to medical students that found to have positive attitude towards item 'the importance to have knowledge about CAM as a student or future-practicing health professionals'. This was reinforced by the total mean score of nursing students that was 36.61 (3.181) higher than medical students with 33.59 (3.801), thus implied that nursing students have more positive attitude towards CAMs compared to medical students.

\section{Differences of Practice of CAMs among Nursing and Medical Students}

From the Table 3, the lowest mean score implies the least practice of CAM in clinical area. Its shown that nursing students practice most in recommend herbal therapies with $2.91(0.292)$ besides diet or nutritional therapies, 2.76 (0.502), and homeopathy, 2.64 (0.653). In comparison with medical students, they practice more to recommend diet or nutritional therapies with the highest mean score was $2.76(0.489)$, followed by relaxation techniques, 2.68 (0.521), and prayer, $2.44(0.594)$. The total mean scored by nursing students regarding the practice of CAMs in clinical area was 39.79 (4.762) higher than medical students with total mean scored only 34.90 (7.190). Most of the items showed a significantly different $(\mathrm{t}$-value $=3.354, \mathrm{p}$-value $=$ $0.001 ;<0.05)$ between nursing and medical students intention to practice CAMs in clinical area.

Table 1: Differences of knowledge of CAMs among nursing and medical students

\begin{tabular}{lcccc}
\hline Items & \multicolumn{2}{c}{ Mean (SD) } & t-value & p-value \\
& Nursing & Medical & & \\
\hline Acupuncture & $3.18(0.465)$ & $2.98(0.651)$ & 1.531 & 0.130 \\
Aromatherapy & $3.36(0.653)$ & $2.93(0.721)$ & 2.701 & 0.009 \\
Chiropractic & $1.42(0.792)$ & $1.54(0.840)$ & -0.587 & 0.559 \\
Creative Therapies (Art, Dance, Music) & $3.39(1.088)$ & $2.41(0.774)$ & 4.519 & $<0.001$ \\
\hline Diet/Nutritional Therapies & $3.58(0.867)$ & $3.12(1.029)$ & 2.020 & 0.047 \\
\hline Herbal Therapies & $3.45(0.711)$ & $3.12(0.812)$ & 1.849 & 0.068 \\
\hline Homeopathy & $2.76(0.936)$ & $2.95(0.921)$ & -0.893 & 0.375 \\
Magnetic Healing & $2.36(0.936)$ & $1.95(0.893)$ & 2.126 & 0.037 \\
\hline Massage Therapy & $3.67(0.816)$ & $3.00(0.806)$ & 3.516 & 0.001 \\
Meditation & $3.67(0.924)$ & $3.05(0.740)$ & 3.195 & 0.002 \\
\hline Prayer & $4.36(0.603)$ & $3.93(0.959)$ & 2.278 & 0.026 \\
Qi Gong & $3.36(0.962)$ & $2.27(0.949)$ & 4.904 & $<0.001$ \\
\hline Reflexology & $3.30(0.918)$ & $3.02(0.790)$ & 1.403 & 0.165 \\
\hline Relaxation Techniques & $4.03(0.637)$ & $3.80(0.928)$ & 1.188 & 0.239 \\
\hline Therapeutic Touch & $3.36(0.822)$ & $2.20(0.980)$ & 5.470 & $<0.001$ \\
\hline Tonic Products (Omega 3, Chicken & $2.94(1.029)$ & $2.88(1.053)$ & 0.252 & 0.802 \\
Essence, etc.) & & & & \\
\hline Total score & $\mathbf{5 2 . 2 1 ( 5 . 9 2 0 )}$ & $\mathbf{4 5 . 1 7 ( 7 . 2 3 4 )}$ & & \\
\hline
\end{tabular}


Table 2: Differences of attitude towards CAMs among nursing and medical students

\begin{tabular}{|c|c|c|c|c|c|}
\hline \multirow[t]{2}{*}{ No. } & \multirow[t]{2}{*}{ Items } & \multicolumn{2}{|c|}{ Mean (SD) } & \multirow[t]{2}{*}{ t-value } & \multirow[t]{2}{*}{ p-value } \\
\hline & & Nursing & Medical & & \\
\hline 1 & CAM is a threat to public health. & $\begin{array}{c}2.97 \\
(1.262)\end{array}$ & $\begin{array}{c}2.68 \\
(1.128)\end{array}$ & 1.031 & 0.306 \\
\hline 2 & $\begin{array}{l}\text { CAM therapies that have not been tested scientifically } \\
\text { should be discouraged. }\end{array}$ & $\begin{array}{c}3.48 \\
(1.064)\end{array}$ & $\begin{array}{c}3.56 \\
(1.141)\end{array}$ & -0.294 & 0.770 \\
\hline 3 & $\begin{array}{l}\text { CAM therapies should be offered to patients only when no } \\
\text { real cause or cure can be found. }\end{array}$ & $\begin{array}{c}2.61 \\
(0.966)\end{array}$ & $\begin{array}{c}2.49 \\
(0.898)\end{array}$ & 0.544 & 0.588 \\
\hline 4 & $\begin{array}{l}\text { All health care professionals should have some knowledge } \\
\text { about the most common CAM therapies. }\end{array}$ & $\begin{array}{c}4.39 \\
(0.556)\end{array}$ & $\begin{array}{c}3.76 \\
(0.916)\end{array}$ & 3.511 & 0.001 \\
\hline 5 & $\begin{array}{l}\text { All health care professionals should be able to advise their } \\
\text { patients about commonly used CAM methods. }\end{array}$ & $\begin{array}{c}4.09 \\
(0.723)\end{array}$ & $\begin{array}{c}3.63 \\
(0.915)\end{array}$ & 2.338 & 0.022 \\
\hline 6 & $\begin{array}{l}\text { While a few CAM approaches may have limited health } \\
\text { benefits, they have no true impact on treatment of } \\
\text { symptoms, condition, and/or diseases. }\end{array}$ & $\begin{array}{c}3.21 \\
(0.893)\end{array}$ & $\begin{array}{c}2.88 \\
(0.900)\end{array}$ & 1.593 & 0.116 \\
\hline 7 & $\begin{array}{l}\text { All health professionals should accept patient's right to use } \\
\text { CAM. }\end{array}$ & $\begin{array}{c}3.88 \\
(0.781)\end{array}$ & $\begin{array}{c}3.73 \\
(0.895)\end{array}$ & 0.743 & 0.460 \\
\hline 8 & $\begin{array}{l}\text { I hope to have some CAM practices available to patients in } \\
\text { my practice. }\end{array}$ & $\begin{array}{c}3.88 \\
(0.696)\end{array}$ & $\begin{array}{c}3.63 \\
(0.767)\end{array}$ & 1.421 & 0.160 \\
\hline 9 & $\begin{array}{l}\text { CAM practices should be included in my school's } \\
\text { curriculum. }\end{array}$ & $\begin{array}{c}3.85 \\
(0.755)\end{array}$ & $\begin{array}{c}3.34 \\
(0.911)\end{array}$ & 2.564 & 0.012 \\
\hline 10 & $\begin{array}{l}\text { Knowledge about CAM is important to me as a } \\
\text { student/future-practicing health professional. }\end{array}$ & $\begin{array}{c}4.24 \\
(0.561)\end{array}$ & $\begin{array}{c}3.88 \\
(0.748)\end{array}$ & 2.321 & 0.023 \\
\hline & Total & $\begin{array}{c}\text { 36.61 } \\
(3.181)\end{array}$ & $\begin{array}{c}33.59 \\
(3.801)\end{array}$ & & \\
\hline
\end{tabular}

Table 3: Differences of practice of CAMs in clinical area among nursing and medical students

\begin{tabular}{lcccc}
\hline Items & \multicolumn{2}{c}{ Mean (SD) } & t-value & p-value \\
& Nursing & Medical & & 0.793 \\
\hline Acupuncture & $2.36(0.895)$ & $2.41(0.774)$ & -0.263 & 0.213 \\
Aromatherapy & $2.48(0.508)$ & $2.29(0.750)$ & 1.258 & 0.255 \\
Chiropractic & $2.00(0.935)$ & $1.76(0.888)$ & 1.147 & 0.019 \\
Creative Therapies (Art, Dance, Music) & $2.45(0.506)$ & $2.07(0.787)$ & 2.410 & 0.990 \\
\hline Diet/Nutritional Therapies & $2.76(0.502)$ & $2.76(0.489)$ & 0.013 & $<0.001$ \\
\hline Herbal Therapies & $2.91(0.292)$ & $2.17(0.892)$ & 0.4559 & 0.008 \\
Homeopathy & $2.64(0.653)$ & $2.12(0.900)$ & 2.751 & 0.008 \\
\hline Magnetic Healing & $2.30(0.847)$ & $1.76(0.860)$ & 2.738 & 0.041 \\
\hline Massage Therapy & $2.58(0.502)$ & $2.24(0.799)$ & 2.077 & 0.015 \\
Meditation & $2.52(0.508)$ & $2.12(0.781)$ & 2.497 & 0.909 \\
\hline Prayer & $2.45(0.564)$ & $2.44(0.594)$ & 0.114 & $<0.001$ \\
Qi Gong & $2.52(0.667)$ & $1.80(0.813)$ & 4.040 & 0.381 \\
\hline Reflexology & $2.52(0.667)$ & $2.37(0.767)$ & 0.882 & 0.122 \\
\hline Relaxation Techniques & $2.48(0.566)$ & $2.68(0.521)$ & -1.564 & 0.016 \\
\hline Therapeutic Touch & $2.27(0.674)$ & $1.83(0.834)$ & 2.472 & 0.006 \\
\hline Tonic Products (Omega 3, Chicken & $2.55(0.666)$ & $2.07(0.755)$ & 2.819 & 0.001 \\
\hline Essence, etc.) & & & 3.354 & \\
\hline Total & $39.79(4.762)$ & $34.90(7.190)$ & & \\
\hline
\end{tabular}




\section{Discussion}

\section{Differences of CAM knowledge among nursing and medical student}

The highest total mean scored by nursing students indicates they were generally more knowledgeable about CAM than medical students. This finding showed a similarity with Yildirim et al.'s study [1]. This is not surprising as some of CAM modalities already been integrated in the nursing syllabus -'Nursing Intervention Classification' under the Nursing Care Plan Process. However in other study, found that medical students were more knowledgeable in CAM modalities especially in chiropractic, massage therapy, meditation, and herbal therapies [12].

\section{Differences of attitudes towards CAM among nursing and medical students}

Nursing students practice of CAMs in clinical area was higher than medical students which revealed that less of CAM exposure made medical students had less intention to recommend modalities to patients [13]. Nursing students were more likely and have intention to recommend herbal therapies, massage therapy, meditation, diet and nutritional therapy whereas medical students prefer to recommend diet or nutritional therapies. This finding also supports the KAP model which stated that the more powerful knowledge students have regarding CAMs, they more positive they will practice in their clinical area.

\section{Conclusion}

As a conclusion, this study revealed that nursing students compared to medical students generally were more intention to practice CAM in clinical area. However, it is suggested that in the future research, a larger and various sample size can be used for the most accurate findings.

\section{Reference}

1. Yildrim Y, Parlar S, Eyigor S, Sertoz OO, Eyigor C. An analysis of nursing and medical students' attitudes towards and knowledge of complementary and alternative medicine (CAM). Journal of Clinical Nursing. 2009; 19: 1157-1166.

2. World Health Organization (WHO), www.who.int. Accessed on 26 October 2010

3. Kozak LE, Kayes L, McCarty R, Walkinshaw C, Congdon S, Kleinberger J, Hartman V, Standish LJ. Use of complementary and alternative medicine by Washington State hospices. American Journal of Hospice and Palliative Medicine. 2009;25(6):463-468.

4. Nabilla AS, Safura J, Karina R, Noran H, Norizan $M$. Is input in CAM necessary in our medical curriculum? A perspective from a survey on medical practitioners. Med $J$ Malaysia. 2002; 57. Suppl E: 37-43. http://www.ncbi.nlm.nih.gov/pubmed/12733 192. Accessed on 16 July 2010.

5. Joo S, Musselmann B, Miksch A, Rosemann $\mathrm{T}$, Szecenyi J. The role of complementary and alternative medicine (CAM) in Germany- A focus group study of GPs. BMC Health Serv Res.2008; 8: 127.

6. Malaysian Department of Statistics. Statistics on Causes of Death in Malaysia 2007. 2009. www.statistics.gov.my. Accessed on 19 July 2010.

7. Kreitzer MJ, Mitten D, Harris I, Shandeling J. Attitudes towards complementary and alternative medicine (CAM) among medical, nursing, and pharmacy faculty and students: A comparative analysis. Alternative Therapies in Health and Medicine. 2002; 8(6):44-53.

8. Sapp A. Complementary/alternative therapies and nurse practitioner. Unpublished Master's Thesis. University of Missouri, Columbia MO. 1997.

9. Baugniet $\mathrm{J}$, Boon $\mathrm{H}$, Ostbye $\mathrm{T}$. Complementary/alternative medicine: Comparing the views of medical students with students in other health care professions. Family Medicine. 2000. 32(3):178-184.

10. Lie DA, Boker J. Development and validation of the CAM Health Belief Questionnaire (CHBQ) and CAM use and 
attitudes amongst medical students. BMC Medical Education. 2004; 4:2.

11. Williams CP. Nutrition Knowledge, Attitudes, and Food Choices of College Students (dissertation).Buffalo. New York: Faculty of D'Youville College; 2008.

12. Tzeng YL. A study on nursing staff's knowledge, attitude, and behavior, and their related factors toward Chinese medicine. Journal of Nursing (China). 1999; 46(6):5770.

13. Chez RA, Jonas WB, Crawford C. A survey of medical student's opinions about complementary and alternative medicine. American Journal of Obstetrics and Gynaecology. 2001; 185:754-757. 